\title{
Article \\ Efficient Light Trapping from Nanorod-Like Single-Textured Al-Doped ZnO Transparent Conducting Films
}

\author{
Jiang Zhu, Daqiang Hu *, Ying Wang *, Chunlei Tao, Hongbao Jia (D) and Wenping Zhao \\ School of Science, University of Science and Technology Liaoning, Anshan 114051, China; \\ zhujiang@ustl.edu.cn (J.Z.); taochunlei19980615@163.com (C.T.); jiahongbao@ustl.edu.cn (H.J.); \\ zhaowp@ustl.edu.cn (W.Z.) \\ * Correspondence: hudq@ustl.edu.cn (D.H.); wangy@ustl.edu.cn (Y.W.)
}

check for updates

Citation: Zhu, J.; Hu, D.; Wang, Y.; Tao, C.; Jia, H.; Zhao, W. Efficient Light Trapping from Nanorod-Like Single-Textured Al-Doped ZnO Transparent Conducting Films. Coatings 2021, 11, 513. https:// doi.org/10.3390/coatings11050513

Academic Editor: Barbara Vercelli

Received: 20 March 2021

Accepted: 25 April 2021

Published: 27 April 2021

Publisher's Note: MDPI stays neutral with regard to jurisdictional claims in published maps and institutional affiliations.

Copyright: (c) 2021 by the authors. Licensee MDPI, Basel, Switzerland. This article is an open access article distributed under the terms and conditions of the Creative Commons Attribution (CC BY) license (https:// creativecommons.org/licenses/by/ $4.0 /)$.

\begin{abstract}
Nanorod-like single-textured Al-doped $\mathrm{ZnO}(\mathrm{AZO})$ transparent conducting films were prepared by the simple hydrothermal growth of AZO nanorods on AZO seed layers. The structures, morphologies, optoelectronic properties and light trapping abilities of the AZO films were investigated. The morphological changes of single-textured AZO films depending on growth temperature were shown. Above all, the relation between light trapping abilities and surface morphologies of the single-textured AZO films was studied in detail. The nanorod-like single-textured AZO films prepared at $100{ }^{\circ} \mathrm{C}$ exhibited low resistivity, high total transmittance and remarkable enhancement of haze value, which can be acted as transparent electrodes for improving the conversion efficiency of Si-based thin film solar cells.
\end{abstract}

Keywords: Al-doped $\mathrm{ZnO}$; transparent conducting films; texture; light trapping ability

\section{Introduction}

Recently, solar cells have been applied extensively in various fields. Among these solar cells, Si-based thin film solar cells have good application prospects due to their unique advantages, such as low cost and simplified technological process. As we all know, improving the conversion efficiency has great practical significance for solar cells. As the front electrodes of solar cells, transparent conducting films with light trapping structures can enhance the light scattering ability and increase the path of incident light in the absorption layer, which could effectively improve the conversion efficiency of Si-based thin film solar cells [1,2].

Al-doped $\mathrm{ZnO}(\mathrm{AZO})$ transparent conducting films are more highly desirable for their potential applications compared with $\mathrm{SnO}_{2}: \mathrm{F}$ and $\mathrm{In}_{2} \mathrm{O}_{3}: \mathrm{Sn}$ films, because they have good characteristics, such as abundant resources, non-toxicity, low cost and stability under a hydrogen plasma environment $[3,4]$. Up to now, the crater-like single-textured structures of AZO films, as mainstream light trapping structures, can be obtained by various methods, including wet chemical erosion after sputtering deposition and plasma etching, etc. And the textured AZO films present definite light trapping abilities. In the wet chemical etching process, different etchants are adopted, such as $\mathrm{HCl}, \mathrm{KOH}$ and $\mathrm{NH}_{4} \mathrm{Cl}$ [5-7]. On this basis, the crater-crater-like double-textured AZO films obtained through multiple deposition and etching process have been prepared and can improve the light trapping abilities in the whole range of solar spectrum. But the process would result in the complex and high-cost preparation [8,9]. Similarly, the plasma etching process also has certain requirements for the experimental equipment [10]. As a matter of fact, the textured surface of AZO films can also be provided by nanorod array structures. AZO nanorod structures can be grown by the hydrothermal method, which has many advantages, such as low growth temperature and simple process. Although the nanorod structures of AZO films have already been obtained by many researchers [11-13], the light trapping properties of AZO transparent conducting films with nanorod structures have not been investigated yet. Therefore, in this 
study, we would study the light trapping abilities of nanorod-like single-textured AZO films prepared by the simple hydrothermal method in detail. The systematic study on the effect of the morphologies of nanorod-like single-textured AZO films on the light trapping properties is significant.

In this work, nanorod-like single-textured AZO transparent conducting films were prepared. The preparation of nanorod-like single-textured AZO films started with the sputtering deposition of AZO seed layers, followed by the simple hydrothermal method to grow AZO nanorods on the AZO seed layers. The morphologies, structures, optoelectronic properties and light trapping abilities of AZO films prepared at different hydrothermal growth temperatures were investigated. In particular, the surface morphological changes of single-textured AZO films depending on growth temperature were observed and presented. By controlling the morphologies of AZO films, the relation between light trapping abilities and morphologies of the nanorod-like single-textured AZO films was studied systematically.

\section{Experimental}

Firstly, AZO seed layers were prepared on glass substrates by direct current pulse magnetron sputtering with a $\mathrm{ZnO}: \mathrm{Al}_{2} \mathrm{O}_{3}$ (98 wt $\%: 2 \mathrm{wt} \%$ ) ceramic target (Yanchuang, Shenzhen, China, 99.99\%). Then, high purity Ar was introduced to the chamber, and the sputtering power of $350 \mathrm{~W}$ was maintained. 500-nm-thick AZO films, as seed layers, were obtained for the latter procedures.

Subsequently, AZO nanorods were grown on the surfaces of AZO seed layers directly by the hydrothermal method. $\mathrm{Zn}\left(\mathrm{CH}_{3} \mathrm{COO}\right)_{2} \cdot 2 \mathrm{H}_{2} \mathrm{O}$ (Sinopharm, Shanghai, China, AR), $\mathrm{C}_{6} \mathrm{H}_{12} \mathrm{~N}_{4}$ (Sinopharm, Shanghai, China, $\mathrm{AR}$ ) and $\mathrm{Al}\left(\mathrm{NO}_{3}\right)_{3} \cdot 9 \mathrm{H}_{2} \mathrm{O}$ (Sinopharm, Shanghai, China, AR) were directly used without further purification. As precursors, the aqueous solutions contained $\mathrm{Zn}\left(\mathrm{CH}_{3} \mathrm{COO}\right)_{2} \cdot 2 \mathrm{H}_{2} \mathrm{O}$ and $\mathrm{C}_{6} \mathrm{H}_{12} \mathrm{~N}_{4}$ in equal concentrations of $0.1 \mathrm{M}$. Concurrently, $\mathrm{Al}\left(\mathrm{NO}_{3}\right)_{3} \cdot 9 \mathrm{H}_{2} \mathrm{O}$, as a dopant source, was added into the aqueous solutions. The doping ratio for $[\mathrm{Al}] /[\mathrm{Al}+\mathrm{Zn}]$ was $2 \mathrm{~mol} \%$. After stirring for $60 \mathrm{~min}$, the mixed solution was slowly poured into a Teflon-lined autoclave apparatus with a capacity of $100 \mathrm{~mL}$. And then, the autoclave was sealed and put into an oven for growing at different temperatures for 3h. After growing, the autoclave was cooled to room temperature naturally. The single-textured AZO films prepared at $70{ }^{\circ} \mathrm{C}, 80^{\circ} \mathrm{C}, 90^{\circ} \mathrm{C}$ and $100{ }^{\circ} \mathrm{C}$ were denoted as $\mathrm{T}-70{ }^{\circ} \mathrm{C}, \mathrm{T}-80{ }^{\circ} \mathrm{C}, \mathrm{T}-90^{\circ} \mathrm{C}$ and $\mathrm{T}-100{ }^{\circ} \mathrm{C}$, respectively.

The morphologies of the $\mathrm{AZO}$ films were analyzed by field emission scanning electron microscopy (FESEM, SIGMA HD, Zeiss, Germany) equipped with energy dispersive X-ray spectroscopy (EDX). The crystalline structures and crystallographic properties of the AZO films were identified by X-ray diffraction (XRD, X'Pert, PANalytical, The Netherlands) within a $2 \theta$ range of $10^{\circ}-90^{\circ}$. The total and diffuse transmittance were examined by a U-3310 ultraviolet-visible spectrophotometer with an integrating sphere. A Hall measurement system (HL5500PC, Accent, UK) was utilized to measure the resistivity, carrier concentration and mobility of the AZO films.

\section{Results and Discussion}

\subsection{Structural Properties}

In order to probe the crystal structure and phase purity of the AZO films, the XRD measurement is performed. Figure 1 displays the XRD patterns of the AZO samples prepared at various hydrothermal growth temperatures. All the samples show a high strength and acuminate diffraction peak at $2 \theta$ of about $34^{\circ}$ and a small peak at near $72^{\circ}$, which correspond to the (002) and (004) planes, respectively. All the diffraction peaks are assigned to wurtzite type $\mathrm{ZnO}$ with preferential c-axis orientation, as reported in the JCPDS file (JCPDS No. 36-1451) [14]. No characteristic peaks for impurities such as $\mathrm{Al}_{2} \mathrm{O}_{3}$ are observed. Meanwhile, as the growth temperature rises from $70{ }^{\circ} \mathrm{C}$ to $100{ }^{\circ} \mathrm{C}$, the intensity of the (002) peak is enhanced gradually, indicating that the crystalline quality is getting better and better. Furthermore, it also implies that the increase of hydrothermal growth 
temperature might impel the atoms to move and arrange the $\mathrm{AZO}$ crystal growth along the (002) orientation, and this growth trend could also be observed from the following SEM results.

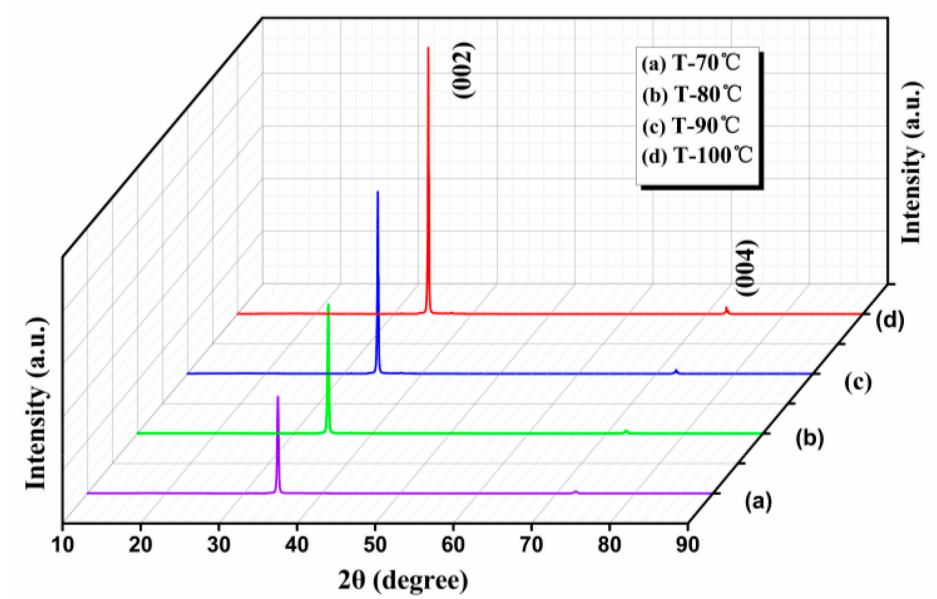

Figure 1. XRD patterns of all the Al-doped $\mathrm{ZnO}(\mathrm{AZO})$ films.

\subsection{Surface Morphology}

The surface SEM images of the AZO films obtained at different hydrothermal growth temperatures are presented in Figure $2 \mathrm{a}-\mathrm{d}$, in which we can see that the surface morphologies of the AZO films are transformed in response to the growth temperature obviously. Figure 2e depicts the cross-sectional view SEM image of the T- $100{ }^{\circ} \mathrm{C}$ sample, in which we can clearly see the nanorod-like structures with lengths of about $1 \mu \mathrm{m}$. The EDX spectrum of the $\mathrm{T}-100{ }^{\circ} \mathrm{C}$ sample is exhibited in Figure 2f, which indicates that $\mathrm{Zn}, \mathrm{O}$ and $\mathrm{Al}$ elements exist in the films. At a low temperature of $70{ }^{\circ} \mathrm{C}$, as shown in Figure $2 \mathrm{a}$, the surfaces of the AZO films show irregular polygonal network-like structures. This may be because the nucleation and growth rates of AZO nanorods are relatively slow at low temperature, consequently suppressing the growth along the c-axis orientation of nanorods. As the growth temperature is increased to $80^{\circ} \mathrm{C}$, as Figure $2 \mathrm{~b}$ depicts, it can be observed that the irregular polygonal network-like AZO structures are reduced and the nanorod-like structures appear. Subsequently, when increasing the temperature to $90^{\circ} \mathrm{C}, \mathrm{AZO}$ nanorods with hexagonal shape predominantly grown along the c-axis orientation can be clearly observed from Figure 2c. Furthermore, we can observe that the AZO nanorods are relatively uniform in size, resulting in a dense surface. Figure $2 \mathrm{~d}$ shows the surface SEM image of the AZO films prepared at $100{ }^{\circ} \mathrm{C}$. The AZO nanorods are still grown perfectly along the (002) plane, with diameters of 70-200 nm. From the above results, with the increase of growth temperature, the morphologies transform from network-like to nanorod-like structures, which corresponds to the increasing intensity of the (002) peak from the XRD results. However, at the growth temperature of $100^{\circ} \mathrm{C}$, we can see that some parts of the nanorods become bitty, and more gaps are observed among the nanorods, as presented in Figure 2d. According to the literature, the competition between growth and erosion of AZO nanorods occurs during the hydrothermal reaction [15]. As the growth temperature rises to a high temperature of $100{ }^{\circ} \mathrm{C}$, the process of decomposing $\mathrm{C}_{6} \mathrm{H}_{12} \mathrm{~N}_{4}$ to produce $\mathrm{OH}^{-}$is promoted, and the growth and dissolution rates of AZO nanorods are decreased and increased, respectively. The erosion occurs on the polar plane (002) plane and side boundary of the AZO nanorods $[15,16]$. This process causes not only the appearance of the gaps among the nanorods, but also the uneven and rough surfaces on the films. The transformation of the observed morphology from network-like to nanorod-like structures will greatly affect the light trapping abilities of AZO films, which will be proved in the later haze results. 

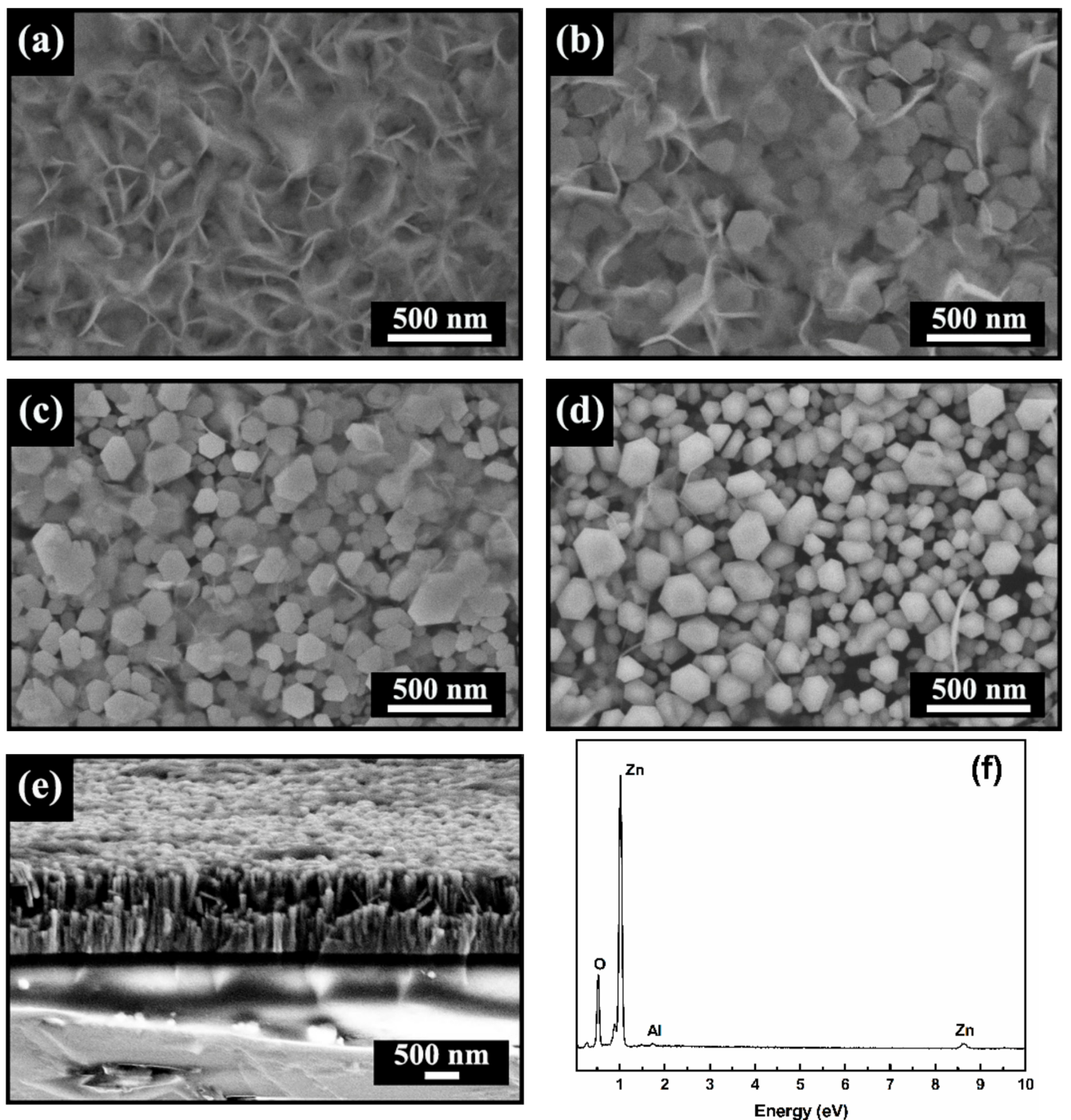

Figure 2. Top view SEM images of the single-textured $\mathrm{AZO}$ films prepared at different growth temperatures: (a) $70{ }^{\circ} \mathrm{C}$, (b) $80^{\circ} \mathrm{C}$, (c) $90^{\circ} \mathrm{C}$, and (d) $100{ }^{\circ} \mathrm{C}$. (e) Cross-sectional view SEM image of the T-100 ${ }^{\circ} \mathrm{C}$ sample. (f) EDX spectrum of the T-100 ${ }^{\circ} \mathrm{C}$ sample.

\subsection{Optical Properties}

Higher average transmittance value in the visible range ( $400-800 \mathrm{~nm})$ is advantageous for the transparent conducting films used as front electrodes. The effect of growth temperature on the optical properties of single-textured AZO films is studied. Figure 3 shows the total (specular + diffused) transmittance spectra of AZO films prepared at different hydrothermal temperatures. The highest average transmittance value is $88 \%$ in the visible range for $\mathrm{T}-70{ }^{\circ} \mathrm{C}$ sample, whereas the minimum average transmittance value is $82 \%$ for $\mathrm{T}-100{ }^{\circ} \mathrm{C}$ sample. Without the influence of glass substrates (transmittance of $\sim 90 \%$ ), the average total transmittance values of all the AZO films can be above $90 \%$, which are helpful for the performance of solar cells. Though the average transmittance value decreases with increasing the growth temperature, it can still satisfy the application of transparent conducting films. Meanwhile, the absorption edge is red shifted in the ultraviolet region, which may be due to the increase of film thickness. 


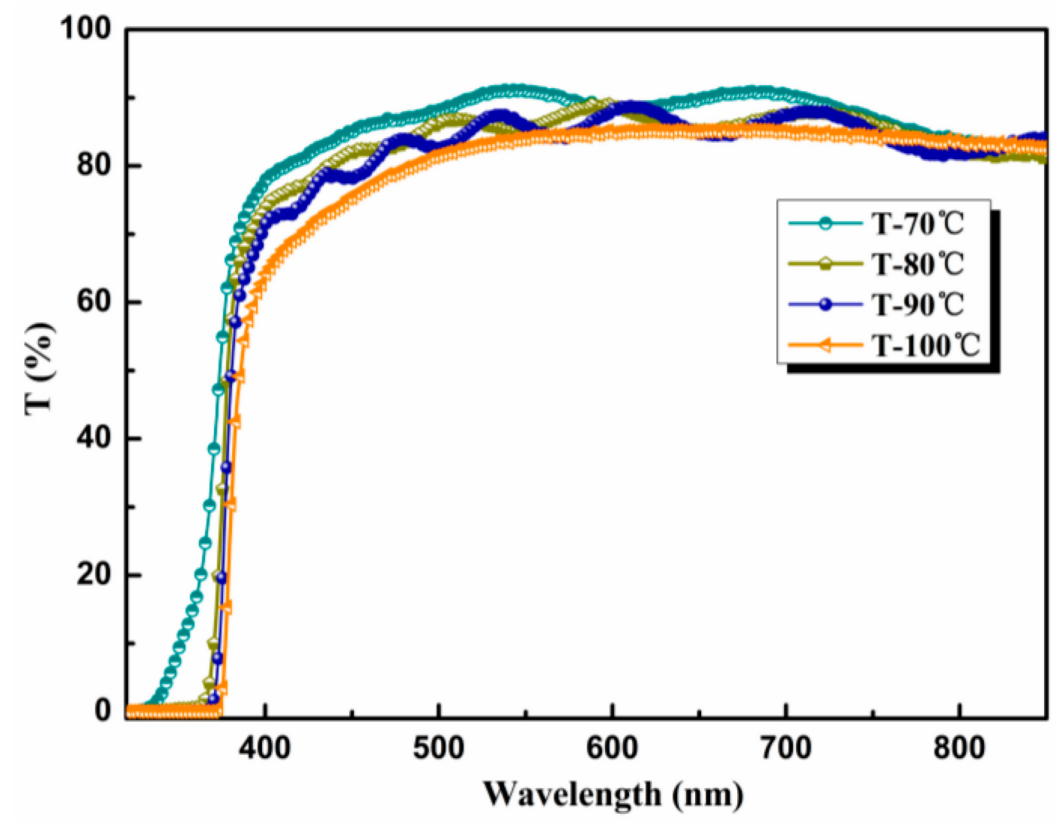

Figure 3. Total transmittance spectra of all the AZO films.

\subsection{Light Trapping Properties}

The light trapping ability is important for the photoelectric conversion efficiency of solar cells. In order to study the relation between light trapping abilities and morphologies, the haze value determined by the total and diffuse transmission $\left(\mathrm{H}_{\mathrm{T}}=\mathrm{T}_{\text {diffuse }} / \mathrm{T}_{\text {total }}\right)$ is measured. It can be seen from Figure 4 that the haze value increases with the increasing growth temperature, revealing that the light trapping abilities of the AZO films are closely related to the surface microstructures of AZO films and the light trapping abilities are further enhanced by the nanorod-like structures of the AZO films. The nanorod-like single-textured AZO films exhibit higher haze value and better light trapping abilities in comparison with the network-like single-textured AZO films. From the SEM images and haze spectra, with the large-scale emergence of nanorod structures on the surfaces, we can see the corresponding increase of haze value. In general, the prominent light trapping ability can be provided by the rougher and less dense surface morphologies, which is confirmed in our studies. From the above SEM results displayed in Figure $2 c, d$, the surfaces of the nanorod-like single-textured AZO films prepared at $90^{\circ} \mathrm{C}$ are denser than those of the AZO films prepared at $100{ }^{\circ} \mathrm{C}$. The dense surfaces would greatly reduce the optical path of the light in the films, which is not favorable for improving light trapping ability. However, the AZO nanorods prepared at growth temperature of $100{ }^{\circ} \mathrm{C}$ show rougher and irregular surfaces, which can provide more scattering centers for the incoming light $[17,18]$. Moreover, at $100{ }^{\circ} \mathrm{C}$, more gaps among the nanorods appear and get wider. Through these gaps and nanorods, more reflection, refraction and scattering of the incident light occur, which can greatly elongate the light path and is more conducive to the light trapping ability [19]. The nanorod-like single-textured AZO films prepared at $100{ }^{\circ} \mathrm{C}$ exhibit higher haze value (0.12) at $550 \mathrm{~nm}$. As reported in our previous work [20], the crater-like singletextured AZO films prepared by wet chemical erosion after sputtering presented a haze value of about 0.13 at $550 \mathrm{~nm}$. As the single-textured films, the nanorod-like AZO films in this study exhibit comparable light trapping abilities and a simpler preparation process compared with the crater-like AZO films. 


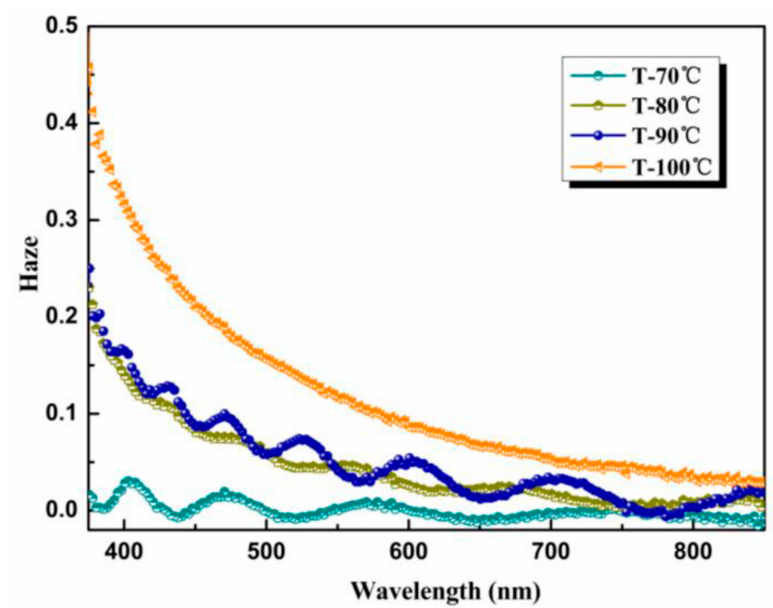

Figure 4. Haze spectra of the AZO films prepared at different growth temperatures.

\subsection{Electrical Properties}

To characterize the electrical properties, the resistivity, carrier concentration and mobility of all the AZO films prepared at different growth temperatures are displayed in Figure 5. From the test results, all the AZO films exhibit n-type conductivity properties. With the increase of temperature, the carrier concentration is almost constant $\left(\sim 10^{20} \mathrm{~cm}^{-3}\right)$. As is well known, the resistivity is inversely proportional to the mobility and the carrier concentration [21]. Because of the almost unchanged carrier concentration, the resistivity is mainly determined by the variation trend of the mobility. From Figure 5, as growth temperature rises from $70^{\circ} \mathrm{C}$ to $100^{\circ} \mathrm{C}$, the mobility increases firstly and then decreases. As a result, the resistivity shows the opposite trend with the increasing temperature. The single-textured AZO films prepared at $70{ }^{\circ} \mathrm{C}$ display the minimum mobility. From the $X R D$ results, we can see that the crystal qualities of the samples get better gradually with increasing the growth temperature. The improvement of the crystal quality can promote the reduction of defects in the films, and thus the impurity scattering is reduced. Therefore, the corresponding mobility can be effectively enhanced at higher growth temperature. In addition, when the growth temperature is increased from $80^{\circ} \mathrm{C}$ to $100{ }^{\circ} \mathrm{C}$, the mobility is slightly decreased. It can be seen from the SEM results that as the growth temperature rises from $80^{\circ} \mathrm{C}$ to $100{ }^{\circ} \mathrm{C}$, the surface roughness of the samples is increased due to the appearance of nanorod structures and gaps among the nanorods, which might lead to the slight decrease of mobility. The resistivities of all the AZO films keep the order of $10^{-3} \Omega \cdot \mathrm{cm}$ and the resistivity of the AZO films prepared at $100{ }^{\circ} \mathrm{C}$ is $2.24 \times 10^{-3} \Omega \cdot \mathrm{cm}$, which is suitable for application in the transparent front electrodes.

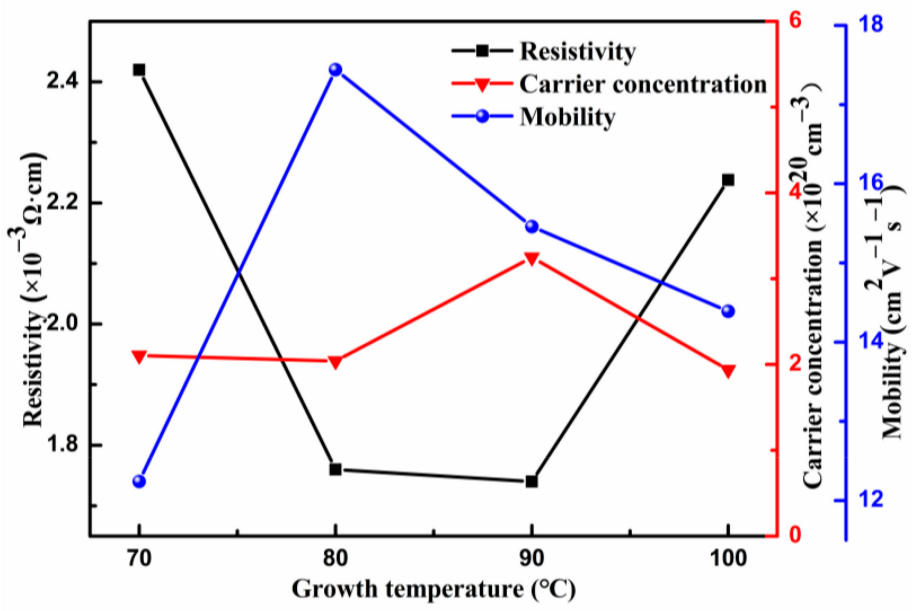

Figure 5. Electrical properties of the AZO films prepared at various growth temperatures. 


\section{Conclusions}

In general, nanorod-like single-textured AZO transparent conducting films with good light trapping abilities were prepared by a simple hydrothermal process on the AZO seed layers. The XRD patterns showed a strong diffraction peak, which indicated the high crystallinity of all the samples. And the (002) preferred orientation peak indicated a typical hexagonal wurtzite structure of $\mathrm{ZnO}$. With the increase of growth temperature, the surface morphologies transformed from network-like to nanorod-like structures. The nanorod-like single-textured $\mathrm{AZO}$ films prepared at $100^{\circ} \mathrm{C}$ displayed higher haze value, which indicated good light scattering abilities. In addition, the films also exhibited a low resistivity in the order of $10^{-3} \Omega \cdot \mathrm{cm}$ and a high total transmittance above $80 \%$. From the results, the nanorod-like single-textured AZO films show satisfactory optoelectronic properties and good light trapping abilities, which are suitable for front electrodes of Si-based thin film solar cells.

Author Contributions: Conceptualization, D.H. and Y.W.; methodology, D.H. and Y.W.; investigation, J.Z., D.H. and Y.W.; writing—original draft preparation, J.Z., D.H. and Y.W.; validation, C.T.; resources, D.H. and Y.W.; writing—review and editing, H.J.; visualization, W.Z.; supervision, Y.W. All authors have read and agreed to the published version of the manuscript.

Funding: This work was supported by the Opened Fund of the State Key Laboratory of Integrated Optoelectronics (grant No. IOSKL2020KF15); the Natural Science Foundation of Liaoning Province (grant No. 2019-ZD-0268); the Excellent Talents Training Project of University of Science and Technology Liaoning (grant No. 2019RC08); the National Natural Science Foundation of China (grant No. 61404070); and the Youth Backbone Teacher Training Project of University of Science and Technology Liaoning.

Institutional Review Board Statement: Not applicable.

Informed Consent Statement: Not applicable.

Data Availability Statement: The data presented in this study are available in this article.

Conflicts of Interest: The authors declare no conflict of interest.

\section{References}

1. Xu, Z.; Huangfu, H.; He, L.; Wang, J.; Yang, D.; Guo, J.; Wang, H. Light-trapping properties of the Si inclined nanowire arrays. Opt. Commun. 2017, 382, 332-336. [CrossRef]

2. Hüpkes, J.; Jost, G.C.E.; Merdzhanova, T.; Owen, J.I.; Zimmermann, T. Coupling and Trapping of Light in Thin-Film Solar Cells Using Modulated Interface Textures. Appl. Sci. 2019, 9, 4648. [CrossRef]

3. Kumar, A.; Ahmad, I. Role of defects and microstructure on the electrical properties of solution-processed Al-doped ZnO transparent conducting films. Appl. Phys. A 2020, 126, 598. [CrossRef]

4. Joung, Y.; Lee, K.; Park, M.; Choi, W. Electrical and Optical Properties of Al-Doped ZnO Transparent Conductive Oxide Films Prepared via Radio Frequency Magnetron Co-Sputtering System. J. Nanosci. Nanotechnol. 2020, 20, 6788-6791. [CrossRef] [PubMed]

5. Lin, G.-S.; Li, C.-Y.; Huang, K.-C.; Houng, M.-P. Using chemical wet-etching methods of textured AZO films on a-Si:H solar cells for efficient light trapping. Mater. Chem. Phys. 2015, 160, 264-270. [CrossRef]

6. Yen, W.T.; Lin, Y.C.; Ke, J.H. Surface textured ZnO:Al thin films by pulsed DC magnetron sputtering for thin film solar cells applications. Appl. Surf. Sci. 2010, 257, 960-968. [CrossRef]

7. Fernández, S.; Abril, O.D.; Naranjo, F.B.; Gandía, J.J. Etching process optimization using $\mathrm{NH}_{4} \mathrm{Cl}$ aqueous solution to texture ZnO:Al films for efficient light trapping in flexible thin film solar cells. Thin Solid Films 2012, 520, 4144-4149. [CrossRef]

8. Jiang, Q.J.; Lu, J.G.; Zhang, J.; Yuan, Y.L.; Cai, H.; Hu, L.; Feng, L.S.; Lu, B.; Pan, X.H.; Ye, Z.Z. Texture-etched broad surface features of double-layered $\mathrm{ZnO}: \mathrm{Al}$ transparent conductive films for high haze values. J. Alloys Compd. 2014, 596, 107-112. [CrossRef]

9. Wang, Y.; Zhang, X.; Bai, L.; Huang, Q.; Wei, C.; Zhao, Y. Effective light trapping in thin film silicon solar cells from textured Al doped ZnO substrates with broad surface feature distributions. Appl. Phys. Lett. 2012, 100, 263508. [CrossRef]

10. Das, G.; Bose, S.; Sharma, J.R.; Mukhopadhyay, S.; Barua, A.K. Texturization of ZnO:Al surface by reactive ion etching in SF $6 / \mathrm{Ar}_{\text {, }}$ $\mathrm{CHF}_{3} / \mathrm{Ar}$ plasma for application in thin film silicon solar cells. J. Mater. Sci. Mater. Electron. 2018, 29, 6206-6214. [CrossRef]

11. Jeong, S.H.; Park, G.C.; Choi, J.H.; Lee, C.M.; Lee, S.M.; Seo, T.Y.; Choi, D.H.; Jung, S.B.; Lim, J.H.; Joo, J. Effect of Al Incorporation on Morphology and Electrical Conductivity of ZnO Nanorods Prepared Using Hydrothermal Method. J. Nanosci. Nanotechnol. 2016, 16, 11272-11276. [CrossRef] 
12. Chiang, J.-L.; Tsai, S.-C.; Kao, M.-C. The pH Sensitivity and Characteristics of AZO Nanorods Based on the Extended-Gate Field-Effect Transistor. J. Comput. Theor. Nanosci. 2015, 12, 825-831. [CrossRef]

13. Sharma, J.R.; Das, G.; Roy, A.B.; Bose, S.; Mukhopadhyay, S. Design analysis of heterojunction solar cells with aligned AZO na-norods embedded in p-type Si wafer. Silicon 2020, 12, 305-316. [CrossRef]

14. Wang, Y.; Hu, D.Q.; Jia, H.B.; Zhong, D.H. Novel double-textured ZnO:Al transparent conducting films with high haze value. Mater. Lett. 2017, 208, 89-91. [CrossRef]

15. Ridhuan, N.S.; Razak, K.A.; Lockman, Z.; Aziz, A.A. Structural and Morphology of ZnO Nanorods Synthesized Using ZnO Seeded Growth Hydrothermal Method and Its Properties as UV Sensing. PLoS ONE 2012, 7, e50405. [CrossRef]

16. Jeon, W.; Leem, J.-Y. Effect of Zn Nitrate Hexahydrate Concentration on ZnO Nanorods Grown from an Electrochemically Oxidized ZnO Seed Layer. J. Korean Phys. Soc. 2018, 72, 1364-1368. [CrossRef]

17. Wang, Y.; Hu, D.; Jia, H.; Wang, Q. Efficient enhancement of light trapping in the double-textured Al doped ZnO films with nanorod and crater structures. Phys. B Condens. Matter 2019, 565, 9-13. [CrossRef]

18. Hussain, S.Q.; Le, A.H.T.; Mallem, K.; Park, H.; Ju, M.; Lee, S.; Cho, J.; Lee, Y.; Park, J.; Cho, E.-C.; et al. Efficient light trapping for maskless large area randomly textured glass structures with various haze ratios in silicon thin film solar cells. Sol. Energy 2018, 173, 1173-1180. [CrossRef]

19. Shan, C.; Zhao, M.; Jiang, D.; Li, Q.; Li, M.; Zhou, X.; Duan, Y.; Wang, N.; Deng, R. Comproved responsivity performance of ZnO films ultraviolet photodetectors by vertical arrays $\mathrm{ZnO}$ nanowires with light trapping effect. Nanotechnology 2019, $30,305703$. [CrossRef]

20. Zhu, J.; Wang, Y.; Hu, D.Q.; Jia, H.B.; Zhao, W.P.; Tao, C.L.; Xu, S.Y. Newfangled crater-nanorod/honeycomb-like double-textured ZnO:Al films with enhanced light trapping. Optik 2021, 228, 166189. [CrossRef]

21. Deng, Z.; Huang, C.; Huang, J.; Wang, M.; He, H.; Wang, H.; Cao, Y. Effects of Al content on the properties of ZnO:Al films prepared by $\mathrm{Al}_{2} \mathrm{O}_{3}$ and $\mathrm{ZnO}$ co-sputtering. J. Mater. Sci. Mater. Electron. 2010, 21, 1030-1035. [CrossRef] 